\title{
Preparation and Characterization of Copper Powders with Sn Coating by the Electroless Plating
}

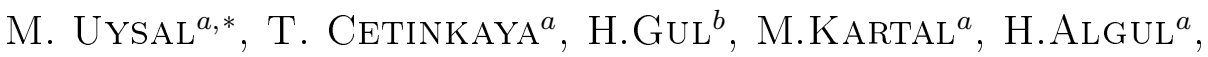 \\ M. TOKur ${ }^{a}, \mathrm{~A} \cdot \mathrm{AlP}^{a}, \mathrm{H} . \mathrm{AkBulut}^{a}$ \\ ${ }^{a}$ Sakarya University Engineering Faculty, Department of Metallurgical \& Materials Engineering, Sakarya \\ ${ }^{b}$ Düzce University Gumusova Vocational School Department of Metallurgical 81850 Duzce

\begin{abstract}
In this work, $\mathrm{Sn}-\mathrm{Cu}$ composite powders were produced using an electroless process. The tin content on the surface of copper powders was varied by using different concentrations of $\mathrm{SnSO}_{4}$ in the plating bath. The surface morphology of the produced $\mathrm{Sn}-\mathrm{Cu}$ composite powders was characterized using scanning electron microscopy (SEM). Energy dispersive spectroscopy (EDS) was used to determine the elemental surface composition of the composites. X-ray diffraction (XRD) analysis was performed to investigate the structure of the Sn-Cu composite powders. The electrochemical performance of $\mathrm{Sn}-\mathrm{Cu}$ nanocomposites was studied by charge/discharge tests.
\end{abstract}

DOI: 10.12693/APhysPolA.127.1106

PACS: 82.47.Aa; 81.15.-z; 73.61.At

\section{Introduction}

Lithium ion secondary batteries have the highest energy density among the commercial batteries, and are used for energy storage in many electric devices, such as mobile phones, laptop computers and digital cameras, owing to the advantages of absence of memory effect, high operation voltage and superior volumetric/gravimetric energy density [1]. The most common anode material used in Li-ion batteries is graphite due to its low cost, availability and durability [2]. In graphitic anodes, the $\mathrm{Li}^{+}$insertion mechanism corresponds to the reversible, progressive intercalation of $\mathrm{Li}^{+}$ions between graphene layers, which allows to reach a theoretical capacity of $372 \mathrm{~mA} \mathrm{~h} \mathrm{~g}^{-1}$ if $\mathrm{LiC}_{6}$. For comparison the experimetal capacity of $350 \mathrm{~mA} \mathrm{~h} \mathrm{~g}^{-1}$ [3] was reached. Alternatively, tin, as a candidate for anode material in lithium-ion batteries, has received much attention because of its almost three times higher specific capacity $\left(994 \mathrm{~mA} \mathrm{~h} \mathrm{~g}^{-1}\right)$, than that of commercially used graphite $\left(372 \mathrm{~mA} \mathrm{~h} \mathrm{~g}^{-1}\right)$ [4]. However, crystallographic studies have demonstrated that when tin-based anodes were used as anode materials, the formation of $\mathrm{Li}_{17} \mathrm{Sn}_{4}$, with an atomic rate of $4.25 \mathrm{Li}$ per $\mathrm{Sn}$, resulted in the large volume change of these metals during lithium insertion/extraction. Decrepitation or fracture of particles of the electrode into smaller pieces normally happens during the intercalation/deintercalation of lithium ions. Approximately $300 \%$ volume expansion of pure tin causes the internal strain of the materials [5]. The large volume variation leads to the pulverization of the electrode and the loss of electrical contact between the active Sn and conductive additives or the current collection performance. All these factors result in deterioration of the

* corresponding author; e-mail: mehmetu@sakarya.edu.tr electrode structure and a decay of electrochemical properties. Therefore, many studies have been focused on tin-based intermetallic alloys such as $\mathrm{Sn}-\mathrm{Ni}, \mathrm{Sn}-\mathrm{Cu}, \mathrm{Sn}-$ $\mathrm{Co}, \mathrm{Sn}-\mathrm{Sb}$ [6], etc. The interface between the active material and the inactive current collector has been found crucial for electrode performances. For this reason, to improve cyclic properties of the electrode, Sn is alloyed with these elements, which are inactive with respect to $\mathrm{Li}$ and hence function only as a matrix and buffer the volume expansion. In this study, to improve the cyclability and capacity performances of Sn electrode; a simple, cost-effective and fair approach is proposed, of synthesizing tin-coated copper particles, using an electroless coating method to preclude electrode pulverization originated from large volume increase during lithiation.

\section{Experiment details}

The initial copper particles with mean particle size of $60 \mu \mathrm{m}$, was used as the substrate for the electroless plating process. Before the production of $\mathrm{Sn}-\mathrm{Cu}$ alloy powders using an electroless process, the surface of the copper powders were pretreated to achieve catalytic activity. First, the surfaces of the copper powders were cleaned with acetone to remove any contaminants. Table I demonstrates the composition and operating conditions of the electroless plating bath for tin coating of copper powders. Firstly, surface of pure copper powders was pretreated to obtain catalytic activity. The surfaces of $\mathrm{Cu}$ powders were cleaned with acetone to remove any contaminants. Later, the surface of copper powder was microetched before tin deposition. At last, copper powders were filtered, washed with distilled water several times. The pretreatment of copper powders was completed after drying of activated powders. After pretreatment process, surface of copper powders was coated with tin by an electroless process. The basic composition of the bath, and the plating conditions are shown in Table I. Plating process was carried out at temperature of 
$70^{\circ} \mathrm{C}$. Plating time was kept constant at $30 \mathrm{~min}$ for all samples. The $\mathrm{pH}$ value of plating bath was controlled continuously in the range between 12-13 during plating, by using $\mathrm{NaOH}$ as a buffer agent. After the plating process, tin coated copper powder was washed up with distilled water and then dried at $60^{\circ} \mathrm{C}$ in a vacuum oven for $12 \mathrm{~h}$. The weight difference of the copper powders before and after plating was measured using an analytic balance with $0.0001 \mathrm{~g}$ resolution to determine the weight gain. The weight gain of the $\mathrm{Sn}-\mathrm{Cu}$ composite powders was expressed using the formula $\Delta W=W_{2}-W_{1}$, where $W_{2}$ and $W_{1}$ are the weight of the Sn-coated copper powders and the uncoated copper powders, respectively. The experiments for coating the surface of the copper powders and determining the weight difference of the tin-coated copper powders after the plating process were repeated several times to optimize the experimental parameters and provide reproducibility of the coatings.

TABLE I

Composition and operating conditions of the plating bath for tin coating on copper powders.

\begin{tabular}{c|c}
\hline \hline $\mathrm{SnSO}_{4}(\mathrm{~g} / \mathrm{l})$ & $15-60$ \\
\hline $\mathrm{NaH}_{2} \mathrm{PO}_{2} \cdot \mathrm{H}_{2} \mathrm{O}(\mathrm{g} / \mathrm{l})$ & 20 \\
\hline $\mathrm{NH}_{4} \mathrm{Cl}(\mathrm{g} / \mathrm{l})$ & 100 \\
\hline $\mathrm{pH}$ & $12-13$ \\
\hline Temperature $\left({ }^{\circ} \mathrm{C}\right)$ & 70 \\
\hline Powder concentration $(\mathrm{g} / \mathrm{l})$ & 10
\end{tabular}

The surface morphology of the $\mathrm{Sn}-\mathrm{Cu}$ powders was characterized by scanning electron microscopy (SEM) (JEOL 6060LV) equipped with energy dispersive spectroscop (EDS). Possible growth planes and the crystallographic relationship of $\mathrm{Sn}-\mathrm{Cu}$ powders were performed by X-ray diffraction (XRD) patterns using a Rigaku D/MAX 2000 X-ray diffractometer. Coin type CR2016 test cells were assembled in argon filled glove box. The prepared electrodes were used as working electrodes, $\mathrm{Li}$ foil used as counter electrode, $1 \mathrm{M} \mathrm{LiPF}_{6}$ dissolved in a mixture of ethylene carbonate (EC) and diethyl carbonate (DEC) (1:1 in volume) was used as the the electrolyte. The working and counter electrodes were separated with polypropylene (PP) separator. Charge-discharge characteristics of the electrodes were tested between $0.02 \mathrm{~V}$ and $1.5 \mathrm{~V}$ at a constant current of $150 \mathrm{~mA} \mathrm{~g}^{-1}$, based on tin and carbon nanotube weight by MTI Battery Tester.

\section{Results and discussion}

Figure 1 presents a SEM image of the Sn-coated copper powders. A relatively continuous uniform and dense tin layer is observed on the surface of the copper powders. It is seen from Fig. 1a-1c that when the concentration of $\mathrm{SnSO}_{4}$ is increased from $15 \mathrm{~g} / 1$ to $60 \mathrm{~g} / 1$, tin deposition on the copper powders increases significantly, which agrees with the results of the weight gain plot presented in Fig. 2. Moreover, the tin grains on the copper powder can also be clearly observed in Fig. 1a. As is clearly shown in Fig. 1b-1c, nearly full coverage of the copper surfaces with a thin layer of $\mathrm{Sn}$ was achieved by using $30 \mathrm{~g} / 1$ and $60 \mathrm{~g} / 1 \mathrm{SnSO}_{4}$, respectively.

Figure 2 shows the influence of the $\mathrm{SnSO}_{4}$ content in the plating solution on the deposited $\mathrm{Sn}$ content in the produced $\mathrm{Sn}-\mathrm{Cu}$ powders. The figure indicates that the weight gain has increased with the increase in the $\mathrm{SnSO}_{4}$ content. This suggests that the Sn content on the copper powder surfaces can be controlled by controlling the concentration of $\mathrm{SnSO}_{4}$. Uysal et al. [7] studied Ni-coated $\mathrm{Al}_{2} \mathrm{O}_{3}$ composite powders using the electroless plating method. They found that the weight of the powders increased with the increase in the $\mathrm{NiCl}_{2} \cdot 6 \mathrm{H}_{2} \mathrm{O}$ content. It can be concluded that if the coating homogeneity and continuity can be controlled for all precursor additions, increasing the $\mathrm{SnSO}_{4}$ content can control the coating thickness of $\mathrm{Sn}$ on copper powders.
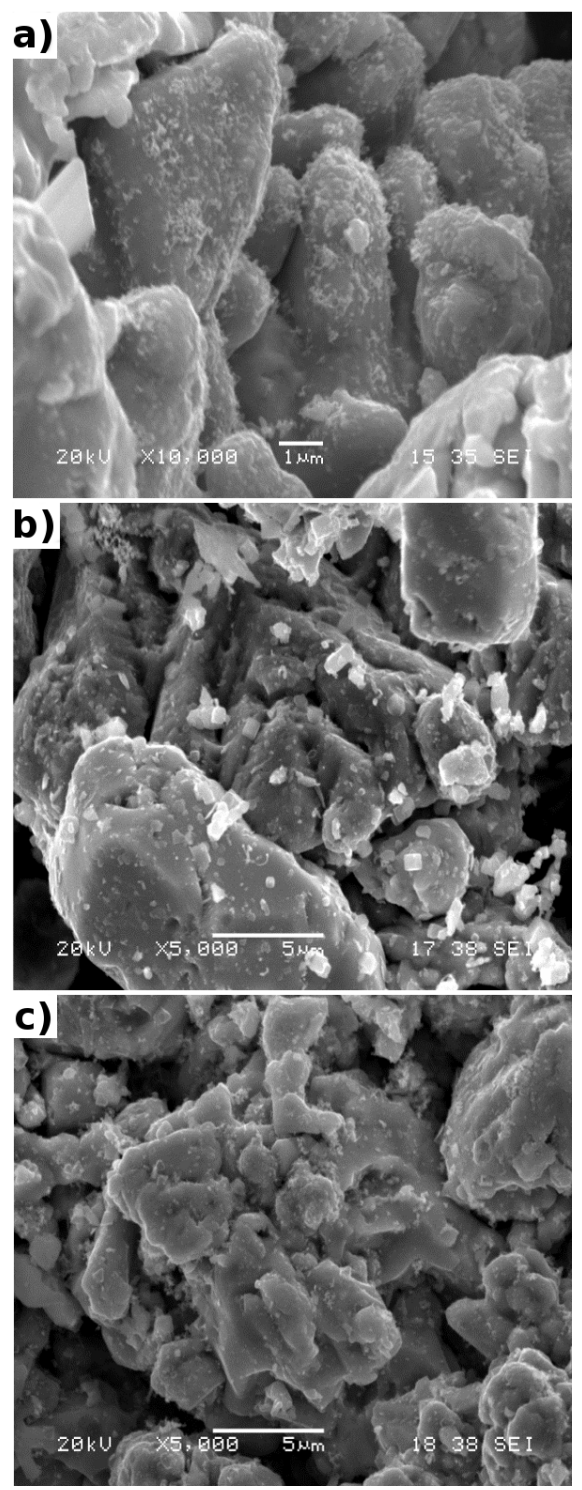

Fig. 1. TSEM images of surface morphology of Sn$\mathrm{Cu}$ composite core-shell structure produced at various $\mathrm{SnSO}_{4}$ amount a) $\left.15 \mathrm{~g} / 1 \mathrm{~b}\right) 30 \mathrm{~g} / \mathrm{l} \mathrm{c)} 60 \mathrm{~g} / \mathrm{l}$. 


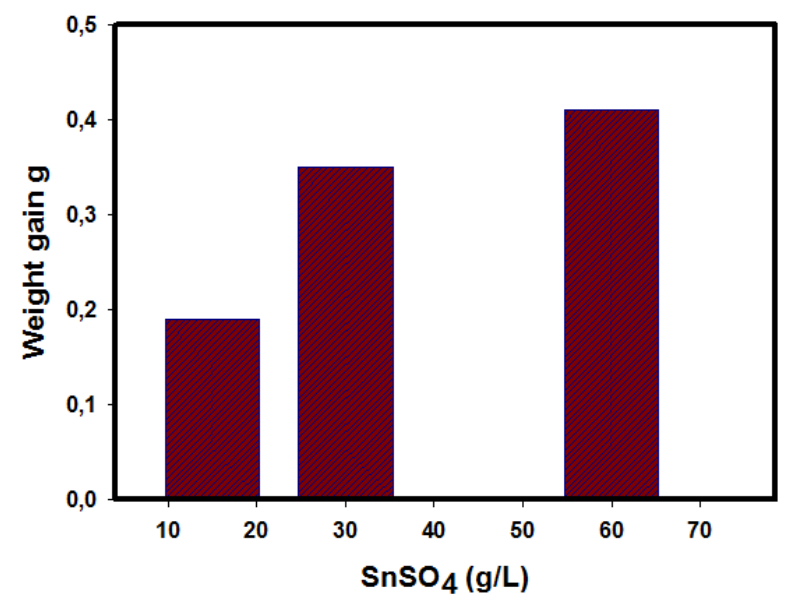

Fig. 2. Effect of the $\mathrm{SnSO}_{4}$ concentration in the plating bath on the weight gain of $\mathrm{Sn}$ on $\mathrm{Sn}$ coated $\mathrm{Cu}$ powders.

The obtained XRD patterns for the $\mathrm{Sn}-\mathrm{Cu}$ core-shell structures are shown in Fig. 3. After coating, typical reflection peaks of tin were observed at $2 \theta$ values of $26.5^{\circ}$, $30.5^{\circ}, 31.9^{\circ}, 43.8^{\circ}, 55.3^{\circ}, 62.5^{\circ}, 64.5^{\circ}, 72.3^{\circ}$, and $79.4^{\circ}$ [7]. Therefore, the XRD patterns of the Sn-Cu evidently confirm that $\mathrm{Sn}$ existed on the surface of the copper powder. It is clearly seen from XRD patterns of $\mathrm{Sn}-\mathrm{Cu}-$ electrodes that tin reflection peak intensity at $2 \theta$ values increases when $\mathrm{SnSO}_{4}$ concentration in the plating bath is increased.

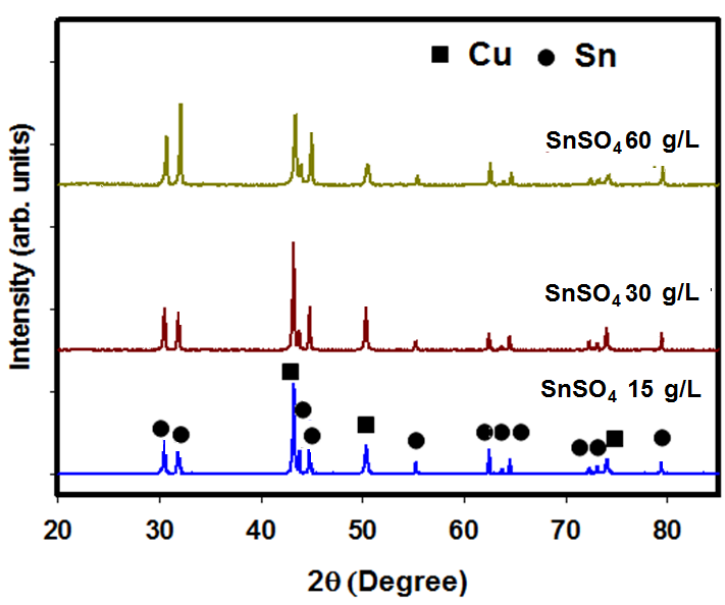

Fig. 3. XRD patterns of core-shell $\mathrm{Sn}-\mathrm{Cu}$ alloy produced at different amount of $\mathrm{SnSO}_{4}$.

Cycling performance and coulombic efficiency of produced $\mathrm{Sn}-\mathrm{Cu}$ alloy electrodes at a current density $150 \mathrm{~mA} / \mathrm{g}$ are shown in Fig. 4. The specific capacities of the produced electrodes were calculated based upon the tin weight, with the help of Fig. 2, because copper is not active in the Li alloying reaction. From this calculation, almost all of the electrodes exhibit the same discharge capacity of approximately 760 for the 1st cycle. When tin is deposited onto copper and the content of tin is increased on the surface of the copper powders, the discharge capacity of the $\mathrm{Sn}-\mathrm{Cu}$ composite electrodes increases with the cycle number because the increased amount of uniform active tin coating on the copper surface, and the buffering effect of copper against electrode pulverization, caused by volume changes. The $\mathrm{Sn}-\mathrm{Cu}$ composite electrodes produced using $60 \mathrm{~g} / 1 \mathrm{SnSO} 4$ exhibited a discharge capacity of approximately $380 \mathrm{mAh} / \mathrm{g}$ after the $30 \mathrm{th}$ cycle.

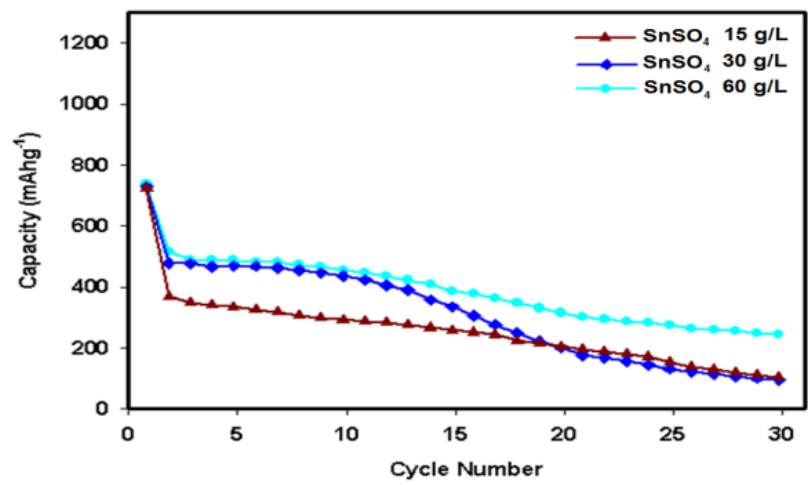

Fig. 4. Cyclic test of tin coated copper electrodes at a constant current density of $150 \mathrm{mAg}^{-1}$.

\section{Conclusions}

- $\mathrm{Sn}-\mathrm{Cu}$ core-shell powders were successfully produced using the electroless deposition technique.

- The deposited tin content on the surface of copper powders increases with increasing $\mathrm{SnSO}_{4}$ concentration in the plating bath.

- Increase of the tin content on the surface of copper powders resulted in improved cycleability and capacity retention of the electrode.

\section{References}

[1] T. Cetinkaya, M.Uysal, M.O. Guler, H. Akbulut, A. Alp, Powder Tech. 253, 63 (2014).

[2] R. Ma, Z. Lu, S. Yang, L. Xi, C. Wang, H.E. Wang, C.Y. Chung, J. Solid State Chem. 196, 536 (2012).

[3] M.J. Wang, C.F. Li, W.J. Lai, S.-K. Yen, Thin Solid Films 520, 6744 (2012).

[4] M. Shafiei, A.T. Alpas, J. Power Sources 196, 7771 (2011).

[5] U. Kasavajjula, C. Wang, A.J. Appleby, J. Power Sources 163, 1003 (2007).

[6] M. Uysal, H. Gul, A. Alp, H. Akbulut, Int. J. Hydrogen Energy 39, 21391 (2014).

[7] M. Uysal, R.Karslioglu, A. Alp, H. Akbulut, Ceramics Int. 39, 5485 (2013). 